\title{
When anticipation beats accuracy: Threat alters memory for dynamic scenes
}

\author{
Michael Greenstein $^{1}$ • Nancy Franklin ${ }^{1}$ Mariana Martins ${ }^{2}$. \\ Christine Sewack $^{1}$ - Markus A. Meier ${ }^{3}$
}

Published online: 23 December 2015

(C) Psychonomic Society, Inc. 2015

\begin{abstract}
Threat frequently leads to the prioritization of survival-relevant processes. Much of the work examining threat-related processing advantages has focused on the detection of static threats or long-term memory for details. In the present study, we examined immediate memory for dynamic threatening situations. We presented participants with visually neutral, dynamic stimuli using a representational momentum (RM) paradigm, and manipulated threat conceptually. Although the participants in both the threatening and nonthreatening conditions produced classic RM effects, RM was stronger for scenarios involving threat (Exps. 1 and 2). Experiments 2 and 3 showed that this effect does not generalize to the nonthreatening objects within a threatening scene, and that it does not extend to arousing happy situations. Although the increased RM effect for threatening objects by definition reflects reduced accuracy, we argue that this reduced accuracy may be offset by a superior ability to predict, and thereby evade, a moving threat.
\end{abstract}

Keywords Threat $\cdot$ Representational momentum $\cdot$ Event memory $\cdot$ Emotion and memory $\cdot$ Scene processing

People are generally good at anticipating simple motion (McLeod \& Dienes, 1996). This ability is critical for effective

Nancy Franklin

nancy.franklin@stonybrook.edu

Stony Brook University, Stony Brook, NY, USA

Columbia University, New York, NY, USA

Ludwig Maximilian University, Munich, Germany tracking, navigation, and other forms of interaction with a dynamic world (Freyd \& Miller, 1992; Hubbard, 2005). It is not surprising, then, that many studies have found anticipation to be essentially built into observation (Freyd \& Finke, 1984). Such an ability is especially critical in threatening situations, when one must, for example, evade a predator or prepare for the actions of a violent rival. Under such circumstances, survival will likely depend not only on one's ability to react, but also to proactively evade, preemptively strike, or rapidly overcome opponents.

Consistent with this reasoning, people show processing advantages for threatening over nonthreatening stimuli (Anderson, Siegel, Bliss-Moreau, \& Barrett, 2011; Devue, Belopolsky, \& Theeuwes, 2011; Ford et al., 2010; Olds, Lanska, \& Westerman, 2014; West, Anderson, \& Pratt, 2009). People are faster, for example, to identify a snake in an array of mushrooms than vice versa (Öhman, Flykt, \& Esteves, 2001). Memory for the location of a stationary threat (Terburg, Aarts, \& van Honk, 2012) is better than memory for nonthreatening counterparts, and this is consistent with more general findings of improved spatial memory for emotional over neutral stimuli (Mather \& Nesmith, 2008).

Similar processing advantages occur for both evolutionarily significant and modern threatening objects (Fox \& Damjanovic, 2006; Fox, Griggs, \& Mouchlianitis, 2007; Loftus, Loftus, \& Messo, 1987; Witt \& Brockmole, 2012). Processing advantages begin preattentively, with threatening objects persisting longer in iconic memory, which allows for greater investment in early perceptual processing (Feldmann-Wustefeld, Schmidt-Daffy, \& Schubo, 2011; Kuhbandner, Spitzer, \& Pekrun, 2011; Phelps, Ling, \& Carrasco, 2006). This heightened prioritization characterizes subsequent search behavior, with threats producing longer spontaneous fixation times than neutral objects (Ford et al., 2010; Loftus et al., 1987). 
Prioritized processing of threatening information should enhance memory for a stationary threat's last observed status. Because the threat's condition is unchanging, accurate memory would optimize future interaction with it. Not only is this the case with the physically stationary threats described above, for which memory of the last observed status of stationary threats is generally accurate, but also in abstract, nonspatial conditions (Lench \& Levine, 2005; MacLeod \& Mathews, 2004; Mathews \& Klug, 1993; Wessel \& Merckelbach, 1997; Zadra \& Clore, 2011).

Faithful memory representation may not always be optimal, however, even for highly survival-relevant situations (see also Klein, Robertson, \& Delton, 2010). Consider immediate memory for dynamic aspects of an unfolding event, which may serve a different function from the sorts of memory discussed above. Whereas memory for past events can facilitate forming new associations, drawing inferences, conveying details to others, and generalizing to similar novel events (e.g., Brewer \& Treyens, 1981; Roediger \& McDermott, 1995), immediate memory during the course of a dynamic event serves primarily to guide one's ongoing actions. Because of this, immediate memory may not show the same sorts of threat-related increases in accuracy as do the other functions listed above. Instead, we predict that other processing biases would emerge that would reflect adaptive anticipation of the threat's next actions. To examine this question, we employed a representational momentum paradigm, which measures distortion toward the future. We describe this phenomenon next.

When viewing simple dynamic scenes, people tend to remember an object's final position as being displaced forward along its path of motion (Freyd \& Finke, 1984; Hubbard \& Ruppel, 1999; Munger, Solberg, \& Horrocks, 1999; Ruppel, Fleming, \& Hubbard, 2009). This representational momentum (RM) effect suggests that memory incorporates the object's anticipated movement. In the classic RM paradigm (e.g., Freyd \& Finke, 1984), static views of (nonthreatening) object configurations are presented in relatively rapid succession to create the impression that one or more objects are moving. At the offset of the final view, participants report the precise final position of the target, typically remembering it as being displaced farther along its path of motion.

Such error has been demonstrated for many different types of objects and movement patterns (e.g., Kerzel, Jordan, \& Musseler 2001; Munger \& Minchew, 2002; Yoshikawa \& Sato, 2008), with the degree of distortion following a number of simple perceptual and conceptual principles (Freyd \& Finke, 1985; Hubbard, 2005, 2014; Reed \& Vinson, 1996; Ruppel et al., 2009; Vinson \& Reed, 2002). For example, the magnitude of forward displacement is a function of both the implied velocity and acceleration (Hubbard, 1995, 2005; Hubbard \& Bharucha, 1988) and can be impacted by semantic information, such as by implied weight (Hubbard, 1997), likely direction of motion (Reed \& Vinson, 1996), context
(Hubbard, 2014), causality (Hubbard \& Ruppel, 2002), and cues suggesting agentive or nonagentive motion (Doerrfeld \& Shiffrar, 2011; see also Wilson, Lancaster, \& Emmorey, 2010).

In the present experiments, we used an RM paradigm to investigate immediate memory for dynamic scenes involving threat. Participants saw simple, abstract visual displays, each consisting of a ring (which corresponded to a moving person with a described intention) and a stationary dot (toward which the ring moved at a constant velocity). The ring's intention (and, thus, threat status) was manipulated in a vignette read by the participants just before they saw the RM display. This allowed the participants to interpret the motion they observed as reflecting specific goal-directed actions (e.g., Heider \& Simmel, 1944), while avoiding many of the complex factors associated with the visual processing of animate stimuli (Freyd \& Miller, 1992). The participants' task was to specify the ring's final position as accurately as possible.

Consistent with the classic RM literature, we predicted forward displacement in memory for both threatening ${ }^{1}$ and nonthreatening conditions. Additionally, if threatening situations prompt observers to anticipate further into the future than they otherwise would, threat should exaggerate the RM effect and lead to even greater forward displacement. That is, immediate memory for the ongoing movement of threatening objects may be optimized not for accuracy, but for evasive responding.

\section{Experiment 1: One moving object (threatening vs. nonthreatening)}

The participants in Experiment 1 were told that each trial would depict schematized video surveillance of a real-world situation involving two people. Each scenario consisted of a stationary dot and a ring that appeared to move along a straight path toward the stationary dot. The moving ring's speed, direction, and ending distance from the dot varied systematically across trials and were independent of each other. Thus, participants could not anticipate an object's ending position simply on the basis of its starting location. Velocity varied across trials, but within a trial, velocity remained constant.

Before each trial, the participant read a brief vignette that provided a conceptual framework (threatening or nonthreatening) within which to interpret the ring's motion. (See Appendix A for examples of each type.) The vignettes described each entity's role in the scenario (e.g., robber [ring] and store clerk [dot], or customer [ring] and store clerk [dot]) and the specific intention of the person who was approaching

\footnotetext{
${ }^{1}$ We will refer throughout the article to situations described as involving malicious intentions, and to rings representing people with the intent to do harm, as "threatening."
} 
the other (e.g., to attack the store clerk or to hand him an item to be purchased). All vignettes ended with a sentence of a standard form: [ring] is approaching [dot] in order to [action]. This sentence always described an action in progress and never described a final position or the completion of a goal.

Again, we predicted that people's memory for the ring's final position would be displaced forward for both threatening and nonthreatening conditions, demonstrating the RM effect. If processing of a threatening scenario prompts observers to further exaggerate the target's forward motion, we should see increased RM for the rings described as having threatening intentions.

\section{Norming}

Participants We recruited 34 participants using Amazon Mechanical Turk to participate in this norming task. Each participant was paid $\$ 0.50$, and none participated in any of the other studies reported here.

Materials and procedure Each participant in the norming study read the text for a subset of the vignettes used in Experiment 1. No participant read both a threatening vignette and a nonthreatening vignette that involved the same object (e.g., axe used in a threatening manner and axe used in a nonthreatening manner). The norming participants performed four tasks for each vignette. First, they estimated how close, in feet and inches, the moving character in the described scenario intended to ultimately be from the stationary character. They made their distance judgment using a slider bar on a scale with the end labels 0 feet and 20 feet. After making a distance estimate, they rated the intensity of the scene, the level of threat in the scene, and the level of happiness in the scene. They made these responses using 7-point Likert scales that ranged from none at all to extreme.

Results There were no differences in participants' estimates of the intended final distance of moving characters from their destination between the threatening $(M=3.26$ feet, $S D=$ $2.46)$ and nonthreatening $(M=3.56$ feet, $S D=1.77)$ vignettes, $t(33)=0.91, p=.42, d=0.14$. People found the threatening vignettes $(M=1.3, S D=0.4)$ to be less happy than the nonthreatening ones $(M=2.95, S D=0.89), t(33)=14.31, p<$ $.001, d=2.39$, as expected. They rated the threatening vignettes as more intense than the nonthreatening ones (threatening: $M=6.06, S D=0.93$; nonthreatening: $M=2.93, S D=$ $0.89), t(33)=12.05, p<.001, d=3.44$. Moreover, they rated threatening vignettes as more threatening than nonthreatening ones (threatening: $M=6.43, S D=0.50$; nonthreatening: $M=$ $1.6, S D=0.72), t(33)=35.83, p<.001, d=7.79$, again as predicted. Thus, although the threatening vignettes were perceived as more threatening, more intense, and less positive than the nonthreatening vignettes, they did not differ in the ultimate ending distances from the destinations that people associated with these scenarios.

\section{Method}

Participants Sixty-eight Stony Brook University undergraduates ( 38 female, 30 male) participated for partial course credit. The participants were assigned randomly to the threatening or the nonthreatening condition. ${ }^{2}$ Half of the participants in each of these conditions always saw a blue ring, and half always saw a green ring. ${ }^{3}$ All other factors varied within participant.

Materials and procedure The experiment was conducted on a Dell desktop computer using Superlab presentation software. Screen resolution was set to 800 pixels $\times 600$ pixels, and participants sat at a comfortable distance for viewing and responding with no positioning restrictions (approximately $65 \mathrm{~cm}$ from the screen). Participants were instructed to suppose that they were employed as an analyst working for the FBI and that they were taking a test to advance to a more elite unit. Each trial represented a schematized security camera video, and the participants' job was to report the final presented position of the moving person. The people in the security videos were depicted as a colored ring and a black dot. The colored ring always appeared to move toward the black dot, which remained stationary. Both the ring and the dot had a diameter of 30 pixels, and the ring had a 10-pixel hollow center. By using rings and dots as surrogates for people, we maintained consistent perceptual conditions between the threatening and nonthreatening conditions. Thus, factors such as size (Hubbard, 1997) and shape (Kelly \& Freyd, 1987) were visually identical for all participants. Additionally, the participants were informed that because they were watching only part of the event, the rings might not actually reach the black dots (in fact, they never did). Participants were instructed to pay careful attention to the rings' final locations, since their responses would be scored for accuracy.

Before each trial, participants read one of 31 three-sentence vignettes about the people depicted in the scene (Appendix A). Each vignette described the person represented by the colored ring as holding a particular object (e.g., a pan) that under most circumstances would not be interpreted as a weapon but that could potentially be used as one. (For a complete list, see

\footnotetext{
${ }^{2}$ Data from nine pilot subjects suggested that participants may have difficulty switching back and forth between threat processing and more neutral information processing from trial to trial. We thus chose to use a between-subjects rather than a within-subject design, to minimize potential spillover effects, both of emotional response and of content.

${ }^{3}$ Ring color was varied in anticipation of Experiment 2, for which we had planned to use two moving objects of different colors.
} 
Appendix B.) For half of the participants, the person holding this potential weapon ${ }^{4}$ was described as approaching the person depicted as a black dot, with the intention of harming him or her (e.g., to attack a former friend with a frying pan). The other half involved a harmless intended interaction (e.g., to give a friend a frying pan). By using a verbal description of the scenario, we were able to avoid factors associated with object complexity (Quinlan, 2013) and manner in which the object was held (Pickel, 1999). Additionally, we attempted to match, as best as possible, the average implied interpersonal distance of the intended threatening and nonthreatening actions within the referent scenarios.

After reading the vignette, participants used the mouse to click the center of the screen. When they did this, the cursor disappeared and the trial began. Each trial consisted of a series of four white displays, followed by a colored visual mask and then a white response screen. Over the course of the trial, a series of screens depicted a ring undergoing implied motion toward a stationary black dot. The initial screen showed the black dot and a colored ring, for $500 \mathrm{~ms}$, allowing participants to view the entire image and note the intended destination of the ring before it started to move. This was followed by a 250 $\mathrm{ms}$ interstimulus interval (ISI), during which participants viewed a white screen containing only the black destination dot. The movement then began with a second presentation of the initial configuration, now for $250 \mathrm{~ms}$, followed by a 250 ms ISI, then the second stimulus screen for $250 \mathrm{~ms}$ (Fig. 1). A 250-ms visual mask followed the fourth stimulus screen. The mask was the same color as the ring, and it covered the entire screen except for the stationary black dot. Thus, the mask removed all evidence of the ring's final position. Finally, the response screen was presented, consisting of the black dot against a white background. A cursor (presented in the form of a 10-pixel cross) appeared at the center of the screen, and participants used the mouse to place the cursor where the center of the moving ring had last been seen and then clicked the mouse to record their response. For $75 \%$ of trials, the program then advanced to the next vignette and trial. For the other $25 \%$, an open-ended question asked either what the ring in the immediately preceding trial had been described as carrying or what it had intended to do. These catch trials were randomly interspersed throughout the experiment to make sure that the participant was attending to the information in the vignettes.

The ring appeared at a unique location on the screen at the beginning of each trial. Across the four stimulus screens, the ring was implied to move in a straight line toward the stationary dot. During the trial, the ring showed implied movement

\footnotetext{
${ }^{4}$ Throughout the article, we will refer to the objects as "potential weapons" so as to disambiguate between objects that could plausibly be used as weapons (e.g., pan) and those that cannot (e.g., sandwich). Whether the object was actually a weapon depended on the described intention within the vignette and was manipulated between subjects.
}

of 210,270 , or $330^{5}$ pixels (or 70,90 , or 110 pixels per stimulus screen) for the "slow," "intermediate," and "fast" trials, respectively. Across the 129 trials (five practice, 124 experimental), the ring was equally likely to move at each of the three speeds (due to a programming error, however, the experimental trials consisted of 42 slow, 41 intermediate, and 41 fast trials).

The ending distance of the colored ring from the stationary dot varied across trials between 99 and 226 pixels, and all 43 of these ending distances (including for practice trials) were distributed equally across the three implied speeds. Finally, the movement was depicted equally often as upward, downward, leftward, and rightward.

\section{Results and discussion}

We removed seven participants' data due to failure to follow instructions, and one participant's because of an error rate above $50 \%$ in the open-ended catch trials. This left 60 participants' data for analysis. Because the destination dot stayed on the screen during the probe task, participants who had attended to the trial would have been able to infer the ring's axis of movement. Therefore, any trial in which a participant indicated a location that deviated by more than 100 pixels orthogonally from the ring's movement axis was removed from the analysis. Furthermore, trials in which a participant took longer than three $S D$ s from their mean response time were also removed from the analysis. Together, these criteria resulted in the removal of less than $2 \%$ of the data.

We measured the displacement of each participant's response from the ring's actual final position. Displacements were defined only with respect to the axis of movement and reflected either positive or negative displacement of the cursor's placement relative to the actual location of the ring's center. Positive values refer to displacement farther along the ring's path of motion, and negative values refer to displacement behind the ring's actual ending location. All data are reported in terms of pixels of displacement from the ring's center.

To test for a classic RM effect, we conducted a singlesample $t$ test using only data from the nonthreatening condition (comparing their displacements to the null-hypothesis prediction of zero pixels of displacement). Participants in the nonthreatening condition displaced the ring forward an average of 22.87 pixels $(S D=17.97)$ along its path of motion, $t(29)=6.97, p<.001, d=2.58$, remembering it as having traveled farther than it actually had, and thus producing a classic RM effect.

\footnotetext{
$\overline{5}$ This made for speeds of 105,135 , and 164 pixels/s, with approximate viewing angles of $4 \% \mathrm{~s}, 5 \%$, and $6 \%$.
} 


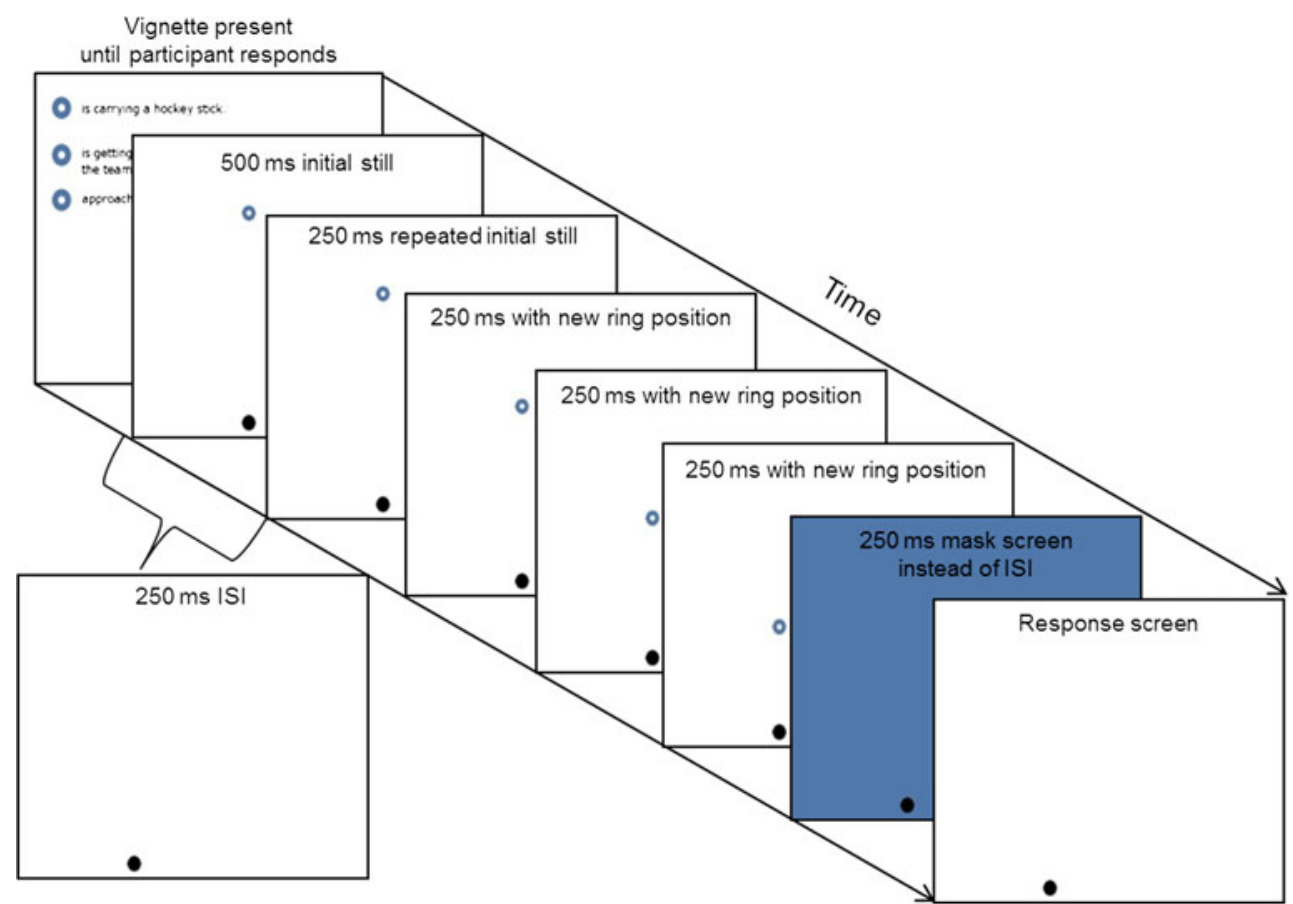

Fig. 1 Each trial began with a description of the characters and goals. After a keypress, the initial configuration was displayed for $500 \mathrm{~ms}$, followed by a 250 -ms ISI during which only the stationary black dot was depicted. Starting with a redisplay of the initial configuration, each

We next examined the extent to which this forward displacement was sensitive to the factors of interest, with the primary goal of investigating the role of threat. Secondarily, and consistent with classic RM, we should find greater forward displacement at greater implied speeds, possibly moderated by boundary effects (Hubbard, 1994; Huttenlocher, Hedges, \& Duncan 1991) as a function of the ring's final distance from its destination. To do this, we consolidated the large number of ending distances into near and far categories, demarcated at the median ending distance of 163.5 pixels. We conducted a 2 (Scene Type: threatening vs. nonthreatening) $\times$ 3 (Ring's Implied Speed: slow, intermediate, fast) $\times 2$ (Ending Distance: near vs. far) $\times 4$ (Direction: up, down, left, or right) $\times 2$ (Ring Color: blue vs. green) analysis of variance (ANOVA). Color and direction were not expected to produce a main effect or to interact with any other factor, nor did they $(p s>.1)$. Thus, we collapsed across both factors for all further analyses.

Impact of threat on RM As predicted, threat increased the magnitude of RM, $F(1,58)=4.24, p<.05, \eta_{\mathrm{p}}^{2}=.068$. Importantly, this suggests that people anticipate the motion of threatening objects ( $M=34.6$ pixels, $S D=25.5)$ to a greater extent than the motion of nonthreatening objects $(M=23.0$ pixels, $S D=18.3$ ), and that this anticipated motion is incorporated into immediate memory for the object's final location.

The magnitude of RM effects was greater when the ring's final position had been far from its destination than stimulus screen appeared for $250 \mathrm{~ms}$, with a 250 -ms ISI. A 250-ms mask screen followed the fourth stimulus screen, and then the response screen appeared and remained until the participant responded

when it had been near, $F(1,58)=99.59, p<.001, \eta_{\mathrm{p}}^{2}=$ .632. This main effect is not surprising, and any of a number of possible reasons might underlie it: greater ending distances from the destination allowing for greater $\mathrm{RM}$, the repulsive influence of landmarks on very near objects (Sheth \& Shimojo, 2001; Werner \& Diedrichsen, 2002), and/or the regression of responses toward intermediate distances. In any case, and most importantly, this main effect was independent of and cannot explain the main effect of threat on RM magnitude.

A main effect of implied speed emerged, $F(2,116)=10.43$, $p<.001, \eta_{\mathrm{p}}{ }^{2}=.152$, with greater forward displacement occurring at the slowest speed $(M=29.73$ pixels, $S D=22.18)$ than at intermediate $(M=28.99$ pixels, $S D=23.07)$ or fast $(M$ $=27.66$ pixels, $S D=23.66$ ) speeds, $F(1,58)=20.28, p<.001$, $\eta_{\mathrm{p}}{ }^{2}=.259$. We have no explanation for this puzzling pattern, which is inconsistent with typical findings in the RM literature (e.g., Freyd \& Finke, 1985). However, an interaction between speed and scene type helps clarify this anomalous finding, $F(2,116)=7.84, p<.001, \eta_{\mathrm{p}}{ }^{2}=.12$. Namely, the greater displacement at slower speeds occurred only for the neutral scenes (slow: $M=25.24, S D=18.62$; intermediate: $M=$ 23.32, $S D=24.74$; fast: $M=20.45, S D=17.66), F(2,58)=$ $13.12, p<.001, \eta_{\mathrm{p}}{ }^{2}=.31$. In contrast, the threatening scenes showed no effect of speed, $F(2,58)=0.16, p=.85$ (Fig. 2).

The results of Experiment 1 show that interpreting a scene as threatening leads to increased forward displacement in memory for the threatening object. The most adaptive, and 


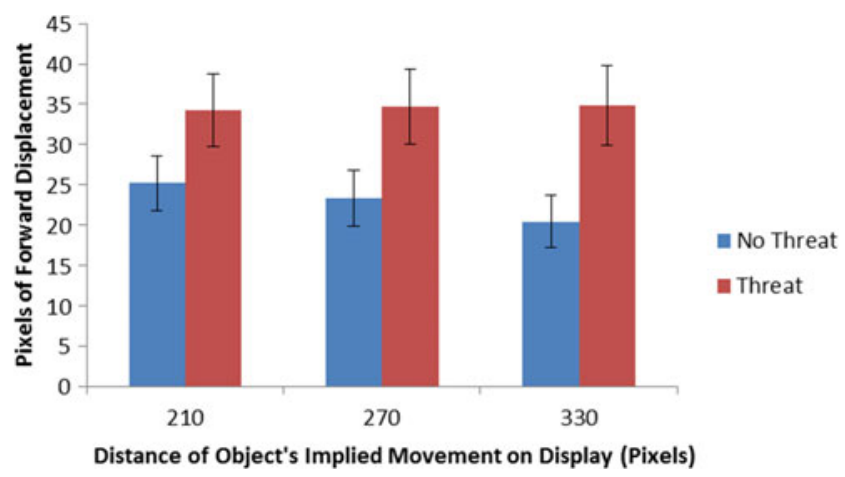

Fig. 2 Relationship between threat and implied speed (slow, intermediate, or fast) in memory for the target's final position (Exp. 1). (Error bars refer to standard error of the mean.)

therefore most likely, response to threatening objects may be evasion. Wherever the object is heading, the observer might best head in the opposite direction. This is the case even if the depicted threat is to a third party, since a dangerous agent's intended target can change abruptly, and an observer can quickly become a victim. The exaggerated forward displacement errors seen in these results are consistent with such a bias and provide greater opportunity to evade the threat. This is in contrast to neutral objects, which are associated with many likely types of anticipated action, including passive observation of, navigation around, or interception of the object, and all of which are optimized by faithful calculation of the object's next position.

\section{Experiment 2: Multiple agents}

The results of Experiment 1 suggest that people anticipate the motion of threatening objects further into the future than they do for nonthreatening ones. However, because the participants in Experiment 1 were presented with scenes that involved a single threatening or nonthreatening object, an equally plausible alternative remains: The heightened tendency to anticipate may apply to all moving objects in the threatening situation, as if a mental simulation of the entire event were advanced uniformly. In Experiment 2, we examined whether this is the case, or whether the effect of threat is exclusive to the threatening object itself. To test this, the participants in Experiment 2 viewed several scenes, each showing two moving objects. Participants viewing threatening scenes observed one threatening and one nonthreatening object within each scene. Participants viewing nonthreatening scenes observed two nonthreatening objects within each scene.

If the increased RM for threatening scenes in Experiment 1 was specific to the threatening objects themselves, then Experiment 2 should show different degrees of displacement for the threatening and nonthreatening objects within a single scene. This would suggest that threatening objects have a special status and that their motion is uniquely exaggerated, perhaps to enable proactive development of an action plan to evade. Indeed, avoidance-related emotions such as fear are known to produce narrowed, local processing at the expense of more global processing (e.g., Basso, Schefft, Ris, \& Dember, 1996; Derryberry \& Reed, 1998; Gasper \& Clore, 2002). One advantage of restricted exaggeration of this sort may be more efficient processing of the threatening object, for which selective attention and action would be adaptive (Friedman \& Förster, 2010; Grafton, Watkins, \& MacLeod, 2012; Harmon-Jones, Price, \& Gable, 2012; Kuhbandner et al., 2011; Morelli \& Burton, 2009).

Alternatively, it is possible that threat would lead to increased extrapolation for the entire scene. The stimuli, after all, depict motion within a single, integrated situation. It is plausible that in extrapolating any element of this physical system, observers would concurrently extrapolate other elements as well. Beyond this, the vignette describing goaldirected behaviors of the agents moving within this scene would encourage the interpretation of this as a single, integrated situation (e.g., Radvansky, 2005). Thus, RM magnitude may be enhanced for all moving objects within a threatening trial. Such a finding would be consistent with the attentionalbroadening and global-processing effects reported by some researchers (e.g., Brunyé, Mahoney, Augustyn, \& Taylor, 2009; Skosnik, Chatterton, Swisher, \& Park, 2000). Finally, exaggerated RM for nonthreatening objects in a threatening situation would have the advantage of predicting potential obstructions to one's evasive or preemptive actions.

\section{Method}

Participants A group of 91 Stony Brook University undergraduates (48 female, 43 male) participated in this experiment for partial course credit. As in Experiment 1, scene type (threatening vs. nonthreatening) was varied between participants, and all other factors were varied within participant.

Materials and procedure The procedure of Experiment 2 was similar to Experiment 1, with the following exceptions. All trials involved two rings, which were depicted as moving simultaneously, each toward its own stationary destination dot. Participants saw a static depiction of the objects' initial positions and initiated the trial with a keypress. At the end of the trial, the visual mask matched the color of one of the two rings, indicating the ring for which participants were to report the final position. The participants in Experiment 2 completed 20 practice trials (because of the increased difficulty of the task), and 84 experimental trials ( 3 Speeds $\times 4$ Directions $\times$ 7 Repetitions). In addition, 12 four-alternative forced choice (4AFC) catch trials immediately followed each of the 12 randomly selected vignettes. 
Because of the presence of two moving objects, we made a number of changes to the stimuli. We used two different ring colors (teal and yellow) and two different destination dots (blue and black). The teal ring always moved toward the blue dot, and the yellow ring always moved toward the black dot. Although the rings had the same diameter as those in Experiment 1, they had a larger (20-pixel) hollow center. The rings never crossed each other's paths, but they otherwise moved independently of each other with respect to distance (and thus speed) and direction. The two rings moved in the same direction, in opposite directions, and in orthogonal directions (e.g., left and up) equal numbers of times across trials. To ensure that the rings never crossed paths, the distances of implied motion were reduced to 90,180 , and 270 pixels. $^{6}$

Because there were two moving rings, each vignette in Experiment 2 described two people. As in Experiment 1, one ring was described as holding a potential weapon (Appendix B), and this ring was described as intending to use the potential weapon in either a threatening manner (e.g., attacking someone with a broken bottle) or a nonthreatening manner (e.g., heading toward someone with a broken bottle to be discarded in the trash). The second ring was always described as holding an inherently innocuous object (e.g., a sandwich). This ring performed the same action regardless of condition (e.g., asking for assistance with a purchase). Each specific combination of potential weapon and inherently innocuous object occurred equally often across participants.

\section{Results and discussion}

The exclusion criteria for Experiments 1 and 2 were the same, except for the acceptable error rate on the catch trials. This was adjusted, since Experiment 2's catch trials were 4AFC rather than open-ended questions, and they occurred immediately after presentation of the story rather than after a trial. Thus, we set a $33 \%$ error rate on catch trials as our criterion for removing a participant's data from the analysis, and we excluded 13 participants using this criterion. We also excluded the data from 12 participants who failed to follow the instructions for reporting ring position. Fewer than $2 \%$ of the individual trial data were removed from the remaining 66 participants. $^{7}$

\footnotetext{
${ }^{6}$ This made for speeds of 60,120 , and 180 pixels/s, with approximate viewing angles of $2 \% \mathrm{~s}, 4 \%$, and $6 \%$ s.

${ }^{7}$ The bulk of the data eliminated from the analysis reflected a lack of attention to the semantic information that was a prerequisite for testing the effects of threat. Thus, we attribute the loss of data largely to a relative lack of emphasis on the importance of semantic information in Experiment 2. We know of no reason to expect that this lack of engagement in the descriptions would be systematically related to the likelihood of classic or exaggerated RM effects.
}

As in Experiment 1, we tested for a traditional RM effect by examining memory for the probed ring's final position within the nonthreatening scenes. We report all data in pixels of displacement. Generally, memory for the final position of the probed ring was displaced forward along its path of motion for both potential weapons $(M=37.19$ pixels, $S D=16.13)$, $t(34)=13.45, p<.001, d=4.61$, and inherently innocuous objects $(M=38.54$ pixels, $S D=17.09), t(34)=13.15, p<$ $.001, d=4.51$. Therefore, the rings showed RM regardless of the type of object they were described as holding.

To test whether the enhanced RM observed in Experiment 1 applies to all aspects of a threatening scene or applies specifically to the threatening object, we conducted a 2 (Scene Type: threatening [which contained one threatening ring and one nonthreatening ring] vs. nonthreatening [which contained two nonthreatening rings]) $\times 2$ (Status of Probed Ring: potential weapon vs. inherently innocuous object) $\times 3$ (Speed: slow vs. intermediate vs. fast) $\times 4$ (Direction: up vs. down vs. left vs. right) $\times 2$ (Color: teal vs. yellow) mixed ANOVA on memory for the probed ring's final position. As in Experiment 1, neither ring color nor direction produced a main effect or an interaction with any other factor $(p s>.1)$, so we collapsed across these factors for all further analyses.

If exaggerated RM occurs only for the threatening object itself, we should see an interaction between the scene's threat status and the individual object's threat status. We found no main effect of scene threat status on the degree of forward displacement, $F(1,64)=0.002$, n.s. That is, exaggerated RM due to threat did not hold at the level of scene, suggesting that people did not represent threatening situations as if they had uniformly advanced further ahead in time. In addition, no main effect emerged to suggest RM differences between the potential weapons as a class and the inherently innocuous objects, $F(1,64)=0.15$, n.s.

We did, however, find the predicted interaction between the threat status of a scene and the probed object's threat status, $F(1,64)=5.25, p<.05, \eta_{\mathrm{p}}{ }^{2}=.076$ (Fig. 3). We take the data from nonthreatening scenes (see Fig. 3, leftmost two bars) to represent baseline displacement magnitudes, uninfluenced by the additional factor of emotional content. We had expected that described objects in the nonthreatening scenes would produce roughly equivalent levels of RM. However, participants may have taken into account the greater physical effort required to carry a baseball bat, tire iron, or golf club, as compared with a sandwich, bottle of juice, or magazine. This may underlie the differences in baseline RM magnitudes. Regardless, given these baseline displacement levels, the reversed pattern for these same objects in the threatening condition (Fig. 3, rightmost two bars) becomes even more remarkable. Thus, threat apparently increases RM specifically for threatening objects, rather than for all objects within a threatening scene. This suggests that in threatening situations, 


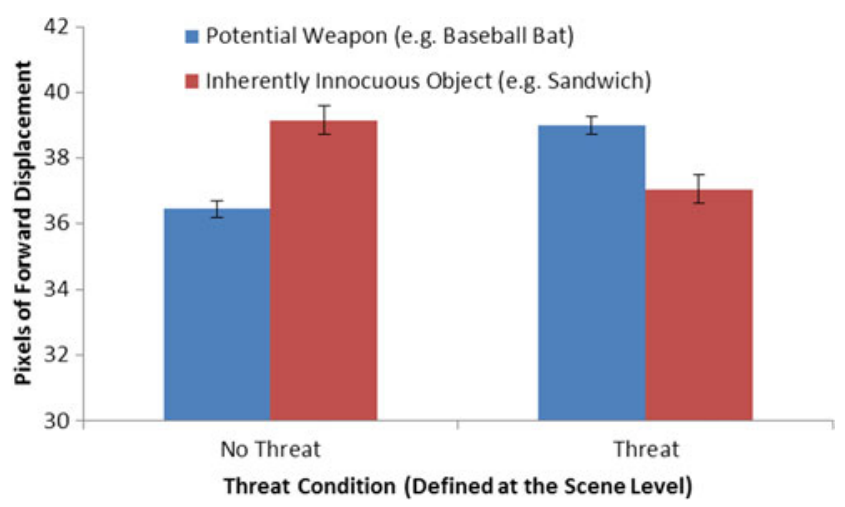

Fig. 3 Magnitude of forward displacement in Experiment 2, as a function of scene threat status and the type of object probed. (Error bars refer to standard error of the mean.)

processing may be prioritized to evade only the object that is threatening.

One might wonder whether the increased RM for threatening objects arose because participants attended more closely to the threatening ring than to the nonthreatening one (Hayes \& Freyd, 2002). Since the rings moved independently and never crossed paths, it would have been challenging to simultaneously track both moving rings closely (e.g., Allen \& Gabbert, 2013). Given that inherently threatening objects (e.g., Loftus et al., 1987; Öhman et al., 2001) and implied threats (e.g., Cutler, Penrod, \& Martens, 1987) disproportionately draw attention, it is possible that visually neutral stimuli (rings) that are interpreted as threatening would do so as well. However, dividing attention between competing objects increases the magnitude of RM (Hayes \& Freyd, 2002), so we would expect that preferential tracking for the threatening ring would have led to better rather than worse location memory, unless the anticipation effects we predicted were also in place. We also would have expected more random responding for the trials that probed inherently innocuous items than for threatening rings, resulting in more eliminated data. Neither of these patterns emerged. On the contrary, participants were no more likely to make major errors in either condition, $t(64)=0.37$, n.s., and innocuous objects in threatening scenes systematically produced classic RM. Therefore, the participants must have kept track of the movements of both objects.

In addition, the classic RM effect of speed emerged, with greater forward displacement for the two faster speeds (intermediate: $M=39.43$ pixels, $S D=16.79$; fast: $M=40.20$ pixels, $S D=17.53)$ than for the slow speed $(M=34.17$ pixels, $S D=$ 14.06), $F(2,128)=33.07, p<.001, \eta_{\mathrm{p}}{ }^{2}=.341$. Speed did not interact with any other factors (all $p \mathrm{~s}>.05$ ).

\section{Experiment 3: Arousing positive (happy) scenes}

Although Experiments 1 and 2 demonstrated increased anticipated motion for threatening relative to nonthreatening stimuli, it is possible that this effect was not due to threatspecific processing. Threats share many of the same properties as other emotional stimuli (Arnell, Killman, \& Fijavz, 2007; Bar-Haim, Lamy, Pergamin, Bakermans-Kranenburg, \& van IJzendoorn, 2007; Calvo \& Lang, 2004; Forgas, 2008; Lerner \& Keltner, 2001), including emotional and motivational properties (e.g., Gasper, 2004; Harmon-Jones et al., 2012). It is possible, then, that any motivated, emotional situation would lead to exaggerated RM, which would suggest that the exaggerated effect is not unique to threat.

If exaggerated anticipation is beneficial across a range of emotionally significant events, then emotions like joyful excitement, for example, might lead to patterns of RM similar to those we have demonstrated for threat. This prediction is consistent with Woody and Teachman (2000), who found that perceived proximity varied with arousal, and with Mather and Sutherland (2009), who found arousal to be a better predictor than valence for location memory binding.

Several findings, in fact, point to the possibility that exaggerated forward distortion should be especially likely for happy scenarios. First, happiness is considered to be an approachrelated emotion (e.g., Gable \& Harmon-Jones, 2011), biasing cognition toward appetitive stimuli. Consistent with this, appealing locations are perceived as being closer than unappealing ones (e.g., Alter \& Balcetis, 2011).

Second, reality monitoring tends to be poorer for positive than for negative events (e.g., Kensinger, O’Brien, Swanberg, Garoff-Eaton, \& Schacter, 2007; Storbeck \& Clore, 2005). If this reduces people's ability to reject their own immediate memory biases, they may have poorer access to accurate memory for the target's final position. Thus, RM effects should increase.

Third, readers' degree of personal engagement with narratives impacts the nature and use of situation models, as well as impacting other downstream cognitive processes (e.g., by means of participatory responses; Albritton \& Gerrig, 1991). If happy scenarios produce higher rates of participatory responses and approach orientation than neutral scenarios, then characters who express happy excitement (e.g., because they have found a lost family heirloom) should produce greater RM magnitude than neutral characters (e.g., who were simply lending their daughter an old necklace).

The findings of Experiments 1 and 2 may, on the other hand, highlight the way in which threat differs from other emotions. In the presence of threat, as we have discussed, evasion of the threat may be an observer's best future action. In such a case, anticipation farther into the future may trump a narrower window of anticipation. It is valuable not just to know where the threat will be in the next moment, but also to know its likely position after that. This emphasis on future behavior may not be as relevant for other emotions. Since people already anticipate the actions of moving objects (Freyd \& Finke, 1985), this may be sufficient for the form of 
precise, coordinated movement motivated by emotions like happiness. According to such reasoning, the happy scenarios of Experiment 3 might not produce exaggerated RM effects. In this experiment, we used a simple two-object design similar to that of Experiment 1 in order to provide the most straightforward opportunity to test these competing predictions.

\section{Norming}

Participants We recruited 70 participants using Amazon Mechanical Turk to participate in this norming task. Each participant was paid $\$ 0.50$.

Materials and procedure The same procedure was used to norm the materials for Experiment 3 as we had used to norm the materials for Experiment 1, except that participants were presented with the vignettes used in Experiment 3.

Results All analyses were conducted using repeated measures $t$ tests. There were no differences between the happy ( $M=$ $1.25, S D=0.63)$ and neutral $(M=1.20, S D=0.51)$ vignettes with regard to perceived threat, $t(69)=1.08, p=.29, d=0.09$. As predicted, people perceived the happy vignettes to be more intense than the neutral vignettes (happy: $M=6.08, S D=1.00$; neutral: $M=3.07, S D=0.88), t(69)=23.27, p<.001, d=$ 3.22 , as well as more happy (happy: $M=6.31, S D=0.69$; neutral: $M=3.47, S D=1.01), t(69)=20.32, p<.001, d=$ 3.28. Participants rated the ultimate ending distance from the destination as being closer for the happy scenarios $(M=1.91$ feet, $S D=1.74)$ than for the neutral ones $(M=2.59$ feet, $S D=$ $1.79), t(69)=4.38, p<.001, d=0.39$.

\section{Method}

Participants A group of 136 Stony Brook University undergraduates ( 85 female, 51 male) participated in this experiment for partial course credit. As in the previous experiments, emotionality was varied between participants, and all other factors were varied within participant.

Materials and procedure The orienting task, objects, and scenes used in Experiment 3 were the same as those in Experiment 1, with a few differences. The vignettes described either neutral or highly positive emotional scenes (Appendix A). The single moving ring was described as holding an object (e.g., a pair of concert tickets) to show or give the black dot, and the vignette ended with the ring being described as approaching the black dot. As with Experiments 1 and 2, the objects depicted in the neutral and happy vignettes were the same (Appendix B). The vignettes in Experiment 3 were six sentences long. This increased length was necessary to establish the emotional contexts of the scenes.

To increase the salience of the semantic content of the vignettes for participants, we increased the number of catch trials to 31 free-response questions. Participants completed four practice trials (one moving in each direction) and 72 experimental trials $(2$ Speeds [210 and 330 pixels] $\times 4$ Directions of Movement, with nine observations in each of these cells). We used 36 different ending distances in this experiment.

\section{Results and discussion}

Using the same exclusion criteria as for Experiment 1, we removed 20 participants' data for failure to follow the instructions. Less than $1 \%$ of the data were removed for the remaining 116 participants (58 in each condition). None of the participants' data were removed due to low catch trial accuracy.

As in Experiments 1 and 2, a single-sample $t$ test showed that participants tended to remember objects as being farther along their path of motion in the neutral condition $(M=21.19$ pixels, $S D=21.67), t(57)=7.47, p<.001, d=1.98$, again demonstrating a classic RM effect.

A 2 (Scene Type: happy vs. neutral) $\times 2$ (Speed: fast vs. slow) $\times 2$ (Ending Distance: near vs. far) ANOVA was conducted to examine whether people anticipated motion to a greater extent for happy than for neutral scenes. Participants did not extend the ring's motion for happy scenarios $(M=$ 21.92 pixels, $S D=17.12)$ to a greater extent than for their neutral counterparts $(M=21.12$ pixels, $S D=21.67), F(1$, $114)=0.41$, n.s. (Fig. 4). That is, we saw no evidence that people extend the motion of objects in happy scenes further into the future in the same manner as they do for threatening scenes. This occurred in spite of the relatively greater statistical power in this study than in Experiments 1 and 2, due to both the larger number of participants and the reduced design complexity. The results suggest that the exaggerated forward displacement found in Experiments 1 and 2 for threatening moving objects may be attributable specifically to the processing biases associated with threat, rather than to processing biases that cut across a broader range of emotionally arousing situations. Despite the approach motivation typically associated with happiness, the anticipated actions associated with happiness still favor relatively more accurate immediate memory for positions within a dynamic scene. That is, in a happy situation, observers are more likely to want to interact with things than to evade them, and interaction is best served by accurately predicting where objects will be next. Consistent with Experiment 1, rings whose motion ended farther from the destination dot produced greater forward displacement $(M=$ 28.28 pixels, $S D=25.86$ ) than did rings whose motion ended closer $(M=14.92$ pixels, $S D=13.94), F(1,114)=121.47, p<$ 


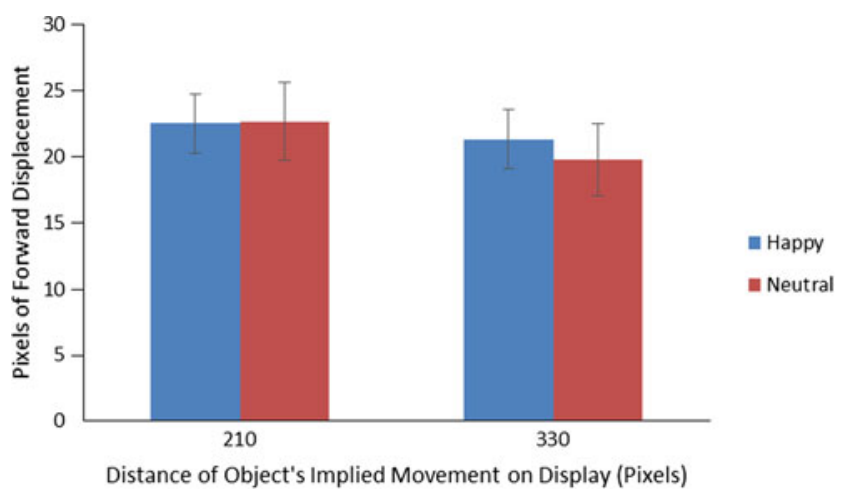

Fig. 4 Representational momentum for happy and neutral scenes in Experiment 3. (Error bars refer to standard error of the mean.)

$.001, \eta_{\mathrm{p}}{ }^{2}=.516$. In contrast to typical findings in the literature, and consistent with Experiment 1, slow rings $(M=22.58$ pixels, $S D=19.94)$ produced greater forward displacement than did fast rings $(M=20.52$ pixels, $S D=19.06), F(1,114)$ $=41.88, p<.001, \eta^{2}=.269$.

Before considering a null hypothesis, it is important to determine whether the experiment has the requisite power to detect an effect. Because we used the same stimuli as in Experiment 1, for the power analysis we used the observed effect size from Experiment $1\left(\eta_{\mathrm{p}}{ }^{2}=.068\right)$, which amounts to a medium effect (Cohen, 1992). We determined that we would need to run 108 participants to obtain a power of .8 . Thus, the 116 participants whose data were included should have been enough to detect an effect, had one existed. Furthermore, because we were able to detect effects in the other analyses (i.e., speed and ending distance), we believe we achieved sufficient power to find an effect of happiness on RM if one existed. To test this further, we examined the posterior probability of the prediction under investigation (i.e., that happiness would exacerbate RM magnitude) by using the JASP statistical software (Love et al., 2015) to compute an inverse Bayes factor $\left(\mathrm{BF}_{10}\right)$. This is represented as an odds ratio in which a value of 1 indicates equal likelihood of the null $\left(\mathrm{H}_{0}\right)$ and alternative $\left(\mathrm{H}_{1}\right)$ hypotheses. Values greater than 1 indicate more evidence for $\mathrm{H}_{1}$, and values less than 1 indicate more evidence for $\mathrm{H}_{0}$ (Jarosz \& Wiley, 2014). As predicted, this analysis favored the absence of an effect $\left(\mathrm{BF}_{10}=0.622\right)$, with $\mathrm{H}_{0}$ being 1.6 times more likely to hold than $\mathrm{H}_{1}$.

The purpose of Experiment 3 was to examine the possibility that the observed effect of threat could simply be attributed to emotional arousal or to the depiction of motivated, directed action. Despite reflecting approach-oriented, intense, and goal-directed action, the happy scenarios failed to increase forward displacement beyond baseline levels from neutral scenarios. Thus, the systematic RM exaggeration observed in Experiments 1 and 2 may be unique to situations (like threat) in which anticipating further into the future would provide the most effective guidance for behavior.

\section{General discussion}

Over the course of three experiments, participants viewed abstracted displays of moving objects and then indicated a target object's final position. Across all experiments and conditions, participants displaced the moving rings forward in memory, consistent with classic RM effects (Freyd \& Finke, 1985; Hubbard \& Ruppel, 1999; Ruppel et al., 2009). In Experiments 1 and 2, this forward displacement was greater when observers considered the probed ring to represent a threatening agent than when they did not. Importantly, this effect occurred only for the threatening objects within threatening scenes, rather than for all objects within the threatening scene. That is, people projected the actions of threatening objects further ahead in time than the actions of nonthreatening objects within the same event, which would allow for more efficient calculation of the motion path of greatest significance.

In contrast, arousing happy vignettes (Exp. 3) did not systematically exaggerate forward displacement in memory for the ring's final position. Instead, the magnitude of RM was comparable to that produced by neutral vignettes. This is consistent with memory biases that would be expected to best serve the demands of happy situations, which are more likely to involve coordination with a target than evasion.

The present work suggests that the relationship between the emotional significance of an event and the optimal memory representation for that event may be complex. Scenarios involving threat are more salient than those involving mundane activity, yet immediate memory accuracy for position was impaired rather than enhanced in the present study. We argue that, whereas the optimal representation of a static threat may be one that accurately reflects its actual location (Mather \& Nesmith, 2008; Mather \& Sutherland, 2011), the optimal representation of a dynamic threat may be one that involves effective anticipation of its motion. This broad principle regarding optimized processing has parallels in other literatures. For example, findings concerning flashbulb memory (e.g., Talarico \& Rubin, 2003) and the impact of stress on memory for detail (e.g., Deffenbacher, Bornstein, Penrod, \& McGorty, 2004) similarly demonstrate adaptive reprioritization of processing toward survival relevance.

Our findings are consistent with the principles of the common coding of events (e.g., Hommel, Müsseler, Ashersleben, \& Prinz, 2001; Prinz, 1984), embodied cognition (Winkielman, Niedenthal, \& Oberman, 2008), and neointernalization theories of RM, whereby forward displacement reflects higher-order processes that are sensitive to anticipated motor activity (Hubbard, 2010). Evasion is an optimal response to threat, and evasion benefits less from precise knowledge of where the threat will be in the next moment than from the ability to predict and direct one's actions away from the threat's likely extended path. Indeed, there is substantial 
evidence that the planning of an action, including actions associated with threat evasion, shares neural resources with perception (Hommel et al., 2001). Given this close connection between observational and behavioral systems, it is not surprising that observing a threat's motion would facilitate action planning in the way our data suggest it might. In particular, this integrated common coding system would allow computation of the sensory consequences of various possible responses and selection of one that would maximize the distance between oneself and the threat in the future. Because selecting the direction of flight from a threat involves a substantial initial commitment, the cost of an incorrect action decision could be high.

There are a number of reasons why the results reported in the present study may actually underestimate the magnitude of the effect. First, the dots used in these experiments served as boundaries that participants knew (through the instructions) that the rings never reached. If this is the case, trials in which the ring ended close to the dot may have led to repulsion effects, eliminating or mitigating RM (Huttenlocher, Hedges, \& Duncan 1991). Second, our participants witnessed abstracted depictions of hypothetical threats against fictitious others while adopting the perspective of a technician. This would be expected to reduce the experience of threat, as compared to a situation in which the threat was aimed more directly at them. Therefore, we would expect that the bias observed in Experiments 1 and 2 might become more pronounced if a first-person experience of threat were involved. In particular, people should be biased to anticipate the motion of an approaching threat and misremember it as having come closer to themselves than it actually had. Indeed, related effects have been reported for spider stimuli (Cole, Balcetis, \& Dunning, 2013; Harber, Yeung, \& Iacovelli, 2011; Witt \& Sugovic, 2013). Third, our displays of rings and dots on otherwise blank backgrounds were schematized, simple, and predictable in their content, and our predisplay descriptions conveyed threat only conceptually (Freyd \& Finke, 1985; Hubbard, 1995, 2005; Laney, Campbell, Heuer, \& Reisberg, 2004; Laney, Heuer, \& Reisberg, 2003; Vinson \& Reed, 2002). Thus, our paradigm, which provided for optimal experimental control and comparability between conditions, had rather low ecological validity with respect to threatening situations. We would expect that under circumstances that more accurately depicted realistic threats with realistic stimuli, the effects reported here might increase. Fourth, our results collapsed across many repetitive trials of similar content, and participants may have habituated to some extent to the interpretation of threat over the course of the session. Nevertheless, RM increased as a function of threat in spite of these design decisions.
Finally, it may be of value to consider how individual differences may lead to deviations from the general pattern of responses observed here. Some populations, for example, may be especially disposed to the effects reported here. People with phobias and anxiety disorders show a greater predisposition to expect or detect threats (see also Riskind, Moore, \& Bowlby, 1995). Similarly, people with posttraumatic stress disorder may be even more likely than nondisordered participants to perceive threat, attend to it, and predict its course.

\section{Considering some alternative explanations}

The threat effects found in these studies could conceivably reflect any of a number of different underlying biases, each with its own set of implications for cognition. We will describe three here and explain why we believe they cannot account for our findings.

Bottom-up mechanisms A compelling literature has demonstrated privileged processing for evolutionarily relevant threat stimuli, such as spiders (Öhman et al., 2001), angry faces and gaits (Chouchourelou, Matsuka, Harber, \& Shiffrar, 2006; Frischen, Eastwood, \& Smilek, 2008), and more modern threats such as guns (Loftus et al., 1987). In contrast, the effects shown in the present studies depend on semantic interpretation of a visually neutral situation. We used neither biological motion (Johansson, 1973; Pratt, Radulescu, Guo, \& Abrams, 2010) nor static visual depictions of the threatening objects referred to by the vignettes, so the exaggerated RM we have found can be attributed to neither lower-level perceptual processing nor preattentive processing (see also Kuhbandner et al., 2011; Veuilleumier, 2005).

Inferred ending position One might argue that the final remembered position could have been influenced by an a priori expectation of a closer ending distance for threatening than for nonthreatening agents. Note, however, that our norming study showed no evidence for systematic differences in these a priori expectations. Note also that our norming study did show that people anticipated that happy actions would end at a shorter distance than their comparison neutral actions. However, in spite of this, we did not find exaggerated RM in the happy scenarios. Thus, expectations about default positions within the referent scenario cannot account for our findings.

Increased estimation of duration People tend to overestimate the durations of both positive (Frederickx et al. 2013) and negative (Loftus, Schooler, Boone, \& Kline 1987b) higharousal events, sometimes by a factor of 2 or 3 (Buckhout, Figueroa, \& Hoff, 1975). If two objects move at the same perceived speed, but one does so (seemingly) for longer, then people would experience it as having moved farther. This leads to an intriguing possible explanation for our results, 
but it cannot account either for the selective exaggeration of $\mathrm{RM}$ for the threatening objects within scenes that also contain nonthreatening objects, or for the lack of RM differences in Experiment 3. Presumably, if the perceived duration of the display's movement had driven our findings, then RM should have increased for all objects within both the negative and positive scenes.

\section{Follow-up studies: Thinking further ahead}

The present findings raise several interesting questions that could help us understand how behavioral biases might affect memory biases for dynamic situations like these.

Persistence of the effect Our investigation was limited to immediate memory following the offset of motion, and RM is known to peak at a few hundred milliseconds following stimulus offset (Finke \& Freyd, 1985; Freyd \& Johnson, 1987; Hubbard, 2005). We chose to study immediate memory because of its likely role in guiding immediate action. It is not clear from our findings, however, whether the observed distortions persist for longer than the second or two it took for the participants to respond. Given that location memory is better for emotional than for neutral objects in long-term memory (e.g., Mather \& Nesmith, 2008), it may be that the distortions we see here are self-correcting at intermediate and long delays. Indeed, the effects we have observed here carry value only for a brief moment, after which a readjustment of memory would be best. On the other hand, when errors do exist in localization, they appear to be more persistent for emotional than for neutral stimuli (Novak \& Mather, 2009). Similar persistence for the bias identified in the present study may have important implications, for example, for the accuracy of eyewitness reports following a threatening event (Christianson, Loftus, Hoffman, \& Loftus, 1991).

Confronted threat There are times when confronting the threat is preferred to fleeing. For example, a parent whose child is being menaced may be inclined to challenge the threat rather than flee from it. In this circumstance, the parent might be better served by classic RM, which would better support accurate prediction of the location in the next unit of time, to guide intervention, blocking, or counterattack. Thus, priming a reader to experience this sort of engagement with the threat might lead to a better understanding of the situations that lead to enhanced RM and the functions it best serves.

Postviolence scenario The increased magnitude of RM observed in Experiments 1 and 2 of this article was argued to support immediate and urgent action. The present paradigm can be applied to threatening scenarios in which the attacker has completed the threatened action and is now approaching the exit. Under such circumstances, we would not predict RM exaggeration comparable to that in the present findings.

Static threats in dynamic situations Our experiments modeled situations that we believed most accurately reflected threatening events as they are experienced in the world. However, a large number of threats are actually static, lying in wait for an unknowing victim to encounter them. The lion lying in wait for a victim to pass by, a sharp and unseen cliff, or a buried landmine all represent situations in which a threatening stimulus is not moving, but a moving person may nevertheless encounter it. Given the biases we argue for in this article, we would not predict enhanced RM for the actions of the threatened, moving individual under such circumstances.

Conceptual "movement" If people anticipate the actions of threatening agents further ahead in time, are they more likely to misremember a threatening person's action as having progressed closer to completion, as compared to the same action by a nonthreatening person (Strickland \& Keil, 2011)? To the extent that an increased propensity to predict the threat's future activities can inform other types of survivalrelevant avoidance, we might see increased false memory for completed actions (the assassin succeeding in acquiring the necessary passport) that had actually only been portrayed as goals.

\section{Conclusion}

In the classic RM paradigm, observers are generally found to displace the position of a moving object forward in immediate memory. This systematic distortion in classic RM paradigms may afford optimal action planning, whereby behavior can be closely coordinated with the moving object's anticipated next position. In the present experiments, memory for final position was distorted even farther forward for moving threats. This exaggerated magnitude of the classic RM effect may be uniquely beneficial for threatening situations, wherein an adaptive response may be evasion rather than coordinated action. Thus, anticipation of the threat's action further into the future, although it leads to a larger memory error, may nevertheless serve to optimize behavior.

Author note We are indebted to Tim Hubbard, Cathy Reed, and three anonymous reviewers for their very helpful feedback; to Matt Cruz for his help with stimulus creation; and to Anthony Auriemmo for his contributions to the programming. 
Appendix A: Sample stimuli from each experiment

Experiment 1

Nonthreatening Condition:

Example 1:

is carrying a pan.

is returning it to a friend.

approaches to give them the pan.

\section{Example 2:}

is carrying a knitting needle.

dropped the other needle.

approaches to get it from him.
Threatening Condition:

Example 1

is carrying a pan.

is a short-order cook whose ex-friend just came into the diner.

approaches to pummel him over the head.

Example 2:

is carrying a knitting needle.

- intends to viciously jab a stranger in front of a store.

approaches to attack him.

\section{Experiment 2}

Nonthreatening Condition

Example 1:

is carrying a broken bottle.

is looking to throw it out.

approaches to ask where a garbage can

is.

is carrying a bottle of juice.

is looking to buy a drink.

approaches to ask him a question.

Example 2:

is carrying a golf club.

is on the way to a country club.

approaches to ask if he would like to play a game.

is carrying a stack of paper.

is working hard early in the morning.

approaches to ask him about the morning reports.
Threatening Condition

Example 1:

is carrying a broken bottle.

is attempting to kill all witnesses to a past crime.

approaches to hurt her.

is carrying a box of cereal.

$\mathrm{i}$ is shopping for food.

approaches to ask him for help.

Example 2:

is carrying a golf club.

$\mathrm{is}$ overreacting to taunting after a game.

approaches to beat her.

is carrying a magazine.

is trying to find a bathroom.

approaches to ask him where the bathroom is. 


\section{Experiment 3}

Example 1:

is carrying a lottery ticket.

just found out that he won the lottery. He and his roommate, had split the cost of a few lottery tickets and decided that if they won they would also split the winnings. 0 is excited beyond belief and could not wait to surprise by handing him the ticket!

approaches to give him the lottery ticket.

Example 2:

is carrying a necklace.

just found the necklace in the closet. It had been in the family for decades until it was lost a few years ago. Everyone thought it had been stolen and was gone forever. 0 is ecstatic to have found the heirloom, and immediately goes to the other room where her mother, is. She knows that that will be thrilled!

approaches to give her the necklace.
Example 1:

is carrying a lottery ticket.

- just found out that he has a losing ticket. He isn't surprised by the outcome since the odds of winning are not good. He had bought the ticket with his roommate, checking the ticket himself, just in case.

approaches to give him the lottery ticket.

Example 2:

is carrying a necklace.

- is letting her mother borrow her necklace for the night. Her mother, is going out for the evening but she does not have any jewelry that goes well with her outfit. - remembers she has an old necklace that she thinks might look okay. It isn't her favorite, so if her mother ends up losing it, it won't be a great loss.

approaches to give her the necklace. 


\section{Appendix B: Complete list of potential weapons, inherently innocuous objects, and positive objects used in each experiment}

\section{Experiment 1 (All Potential Weapons)}

\begin{tabular}{lll}
\hline Axe & Hockey stick & Screwdriver \\
Bat & Knife & Pruning shears \\
Candlestick & Nail gun & Shovel \\
Cane & Pan & Skewer \\
Chainsaw & Two-by-four plank & Ski pole \\
Chair & Pitchfork & Sledgehammer \\
Dumbbell & Pool cue & Tennis racquet \\
Flashlight & Rake & Tire iron \\
Golf club & Razor blade & Tripod \\
Hammer & Scissors & Wrench \\
\hline
\end{tabular}

\section{Experiment 2}

\begin{tabular}{ll}
\hline Potential Weapons: & Inherently Innocuous Objects: \\
Hammer & Bottle of juice \\
Baseball bat & Cereal \\
Tire iron & Magazine \\
Broken bottle & Stack of paper \\
Golf club & Sandwich
\end{tabular}

\section{Experiment 3 (All Potentially Positive Objects)}

\begin{tabular}{lll}
\hline Acceptance letter & Concert ticket & Sonogram picture \\
Necklace & Video game & Check \\
Contract & MCAT score report & Newspaper \\
Lottery ticket & Football ticket & Car keys \\
Picture & Graduation confirmation & Baseball \\
Rose & Medal & Boarding pass \\
\hline
\end{tabular}

\section{References}

Albritton, D. W., \& Gerrig, R. J. (1991). Participatory responses in prose understanding. Journal of Memory and Language, 30, 603-626.

Allen, R., \& Gabbert, F. (2013). Exogenous social identity cues differentially affect the dynamic tracking of individual target faces. Journal of Experimental Psychology: Learning, Memory, and Cognition, 39 , 1982-1989.

Alter, A., \& Balcetis, E. (2011). Fondness makes the distance grow shorter: Desired locations seem closer because they are more vivid. Journal of Experimental Social Psychology, 47, 16-21.

Anderson, E., Siegel, E. H., Bliss-Moreau, E., \& Barrett, L. F. (2011). The visual impact of gossip. Science, 332, 1446-1448.
Arnell, K. M., Killman, K. V., \& Fijavz, D. (2007). Blinded by emotion: Target misses follow attention capture by arousing distractors in RSVP. Emotion, 7, 465-477. doi:10.1037/1528-3542.7.3.465

Bar-Haim, Y., Lamy, D., Pergamin, L., Bakermans-Kranenburg, M. J., \& van IJzendoorn, M. H. (2007). Threat-related attentional bias in anxious and nonanxious individuals: A meta-analytic study. Psychological Bulletin, 133, 1-24. doi:10.1037/0033-2909.133.1.1

Basso, M. R., Schefft, B. K., Ris, M. D., \& Dember, W. N. (1996). Mood and global-local visual processing. Journal of the International Neuropsychological Society, 2, 249-255.

Brewer, W. F., \& Treyens, J. C. (1981). Role of schemata in memory for places. Cognitive Psychology, 13, 207-230.

Brunyé, T. T., Mahoney, C. R., Augustyn, J. S., \& Taylor, H. A. (2009). Emotional state and local versus global spatial memory. Acta Psychologica, 130, 138-146. doi:10.1016/j.actpsy.2008.11.002

Buckhout, R., Figueroa, D. L., \& Hoff, E. (1975). Eyewitness identification: Effects of suggestion and bias in identification from photographs. Bulletin of the Psychonomic Society, 6, 71-74.

Calvo, M. G., \& Lang, P. J. (2004). Gaze patterns when looking at emotional pictures: Motivationally biased attention. Motivation and Emotion, 28, 221-243.

Chouchourelou, A., Matsuka, T., Harber, K., \& Shiffrar, M. (2006). The visual analysis of emotional actions. Social Neuroscience, 1, 63-74.

Christianson, S.-Å., Loftus, E. F., Hoffman, H., \& Loftus, G. R. (1991). Eye fixations and memory for emotional events. Journal of Experimental Psychology: Learning, Memory, and Cognition, 17, 693-701. doi:10.1037/0278-7393.17.4.693

Cohen, J. (1992). A power primer. Psychological Bulletin, 112, 155-159. doi:10.1037/0033-2909.112.1.155

Cole, S., Balcetis, E., \& Dunning, D. (2013). Affective signals of threat increase perceived proximity. Psychological Science, 24, 34-40. doi:10.1177/0956797612446953

Cutler, B. L., Penrod, S. D., \& Martens, T. K. (1987). The reliability of eyewitness identification: The role of system and estimator variables. Law and Human Behavior, 11, 233-258. doi:10.1007/ bf01044644

Deffenbacher, K. A., Bornstein, B. H., Penrod, S. D., \& McGorty, E. K. (2004). A meta-analytic review of the effects of high stress on eyewitness memory. Law and Human Behavior, 28, 687.

Derryberry, D., \& Reed, M. A. (1998). Anxiety and attentional focusing: Trait, state, and hemispheric influences. Personality and Individual Differences, 25, 745-761.

Devue, C., Belopolsky, A. V., \& Theeuwes, J. (2011). The role of fear and expectancies in capture of covert attention by spiders. Emotion, 11, 768-775. doi: $10.1037 / \mathrm{a} 0023418$

Doerrfeld, A., \& Shiffrar, M. (2011). Representational momentum varies across objects. Journal of Vision, 11(11), 731. doi:10.1167/11.11. 731

Feldmann-Wustefeld, T., Schmidt-Daffy, M., \& Schubo, A. (2011). Neural evidence for the threat detection advantage: Differential attention allocation to angry and happy faces. Psychophysiology, 48, 697-707.

Finke, R. A., \& Freyd, J. J. (1985). Transformations of visual memory induced by implied motions of pattern elements. Journal of Experimental Psychology: Learning, Memory, and Cognition, 11, 780-794. doi:10.1037/0278-7393.11.1-4.780

Ford, B. Q., Tamir, M., Brunye, T. T., Shirer, W. R., Mahoney, C. R., \& Taylor, H. A. (2010). Keeping your eyes on the prize: Anger and visual attention to threats and rewards. Psychological Science, 21, 1098-1105. doi:10.1177/0956797610375450

Forgas, J. P. (2008). Affect and cognition. Perspectives on Psychological Science, 3, 94-101. doi:10.1111/j.1745-6916.2008.00067.x

Fox, E., \& Damjanovic, L. (2006). The eyes are sufficient to produce a threat superiority effect. Emotion, 6, 534-539. doi:10.1037/15283542.6.3.534 
Fox, E., Griggs, L., \& Mouchlianitis, E. (2007). The detection of fearrelevant stimuli: Are guns noticed as quickly as snakes? Emotion, 7 , 691-696. doi:10.1037/1528-3542.7.4.691

Frederickx, S., Verduyn, P., Koval, P., Brans, K., Brunner, B., Laet, I. D., ... Hofmans, J. (2013). The relationship between arousal and the remembered duration of positive events. Applied Cognitive Psychology, 27, 493-496. doi:10.1002/acp.2926

Freyd, J. J., \& Finke, R. A. (1984). Representational momentum. Journal of Experimental Psychology: Learning, Memory, and Cognition, 10, 126-132. doi:10.1037/0278-7393.10.1.126

Freyd, J. J., \& Finke, R. A. (1985). A velocity effect for representational momentum. Bulletin of the Psychonomic Society, 23, 443-446.

Freyd, J. J., \& Johnson, J. Q. (1987). Probing the time course of representational momentum. Journal of Experimental Psychology: Learning, Memory, and Cognition, 13, 259-268. doi:10.1037/ 0278-7393.13.2.259

Freyd, J. J., \& Miller, G. F. (1992). Creature motion. Paper presented at the 33rd Annual Meeting of the Psychonomic Society, St. Louis, MO.

Friedman, R. S., \& Förster, J. (2010). Implicit affective cues and attentional tuning: An integrative review. Psychological Bulletin, 136, 875-893. doi:10.1037/a0020495

Frischen, A., Eastwood, J. D., \& Smilek, D. (2008). Visual search for faces with emotional expressions. Psychological Bulletin, 134, 662676.

Gable, P. A., \& Harmon-Jones, E. (2011). Attentional consequences of pregoal and postgoal positive affects. Emotion, 11, 1358-1367. doi: $10.1037 / \mathrm{a} 0025611$

Gasper, K. (2004). Do you see what I see? Affect and visual information processing. Cognition and Emotion, 18, 405-421.

Gasper, K., \& Clore, G. L. (2002). Attending to the big picture: Mood and global versus local processing of visual information. Psychological Science, 13, $34-40$. doi:10.1111/1467-9280.00406

Grafton, B., Watkins, E., \& MacLeod, C. (2012). The ups and downs of cognitive bias: Dissociating the attentional characteristics of positive and negative affectivity. Journal of Cognitive Psychology, 24, 3353.

Harber, K. D., Yeung, D., \& Iacovelli, D. (2011). Psychosocial resources, threat, and the perception of distance and height: Support for the resources and perception model. Emotion, 11, 1080-1090.

Harmon-Jones, E., Price, T. F., \& Gable, P. A. (2012). The influence of affective states on cognitive broadening/narrowing: Considering the importance of motivational intensity. Social and Personality Psychology Compass, 6, 314-327.

Hayes, A. E., \& Freyd, J. J. (2002). Representational momentum when attention is divided. Visual Cognition, 9, 8-27.

Heider, F., \& Simmel, M. (1944). An experimental study of apparent behavior. American Journal of Psychology, 57, 243-259.

Hommel, B., Müsseler, J., Ashersleben, G., \& Prinz, W. (2001). The Theory of Event Coding (TEC): A framework for perception and action planning. Behavioral and Brain Sciences, 24, 849-878. doi: 10.1017/S0140525X01000103. disc. 878-937.

Hubbard, T. L. (1994). Judged displacement: A modular process? American Journal of Psychology, 108, 255-274.

Hubbard, T. L. (1995). Environmental invariants in the representation of motion: Implied dynamics and representational momentum, gravity, friction, and centripetal force. Psychonomic Bulletin \& Review, 2, 322-338. doi:10.3758/BF03210971

Hubbard, T. L. (1997). Target size and displacement along the axis of implied gravitational attraction: Effects of implied weight and evidence of representational gravity. Journal of Experimental Psychology: Learning, Memory, and Cognition, 23, 1484-1493. doi: $10.1037 / 0278-7393.23 .6 .1484$

Hubbard, T. L. (2005). Representational momentum and related displacements in spatial memory: A review of the findings. Psychonomic Bulletin \& Review, 12, 822-851. doi:10.3758/BF03196775
Hubbard, T. (2010). Approaches to representational momentum: Theories and models. In R. Nijhawan \& B. Khurana (Eds.), Space and time in perception and action (pp. 338-365). Cambridge: Cambridge University Press.

Hubbard, T. L. (2014). Forms of momentum across space: Representational, operational, and attentional. Psychonomic Bulletin \& Review, 21, 1371-1403. doi:10.3758/s13423-014-06243

Hubbard, T. L., \& Bharucha, J. J. (1988). Judged displacement in apparent vertical and horizontal motion. Perception \& Psychophysics, 44, 211-221. doi:10.3758/BF03206290

Hubbard, T. L., \& Ruppel, S. E. (1999). Representational momentum and the landmark attraction effect. Canadian Journal of Experimental Psychology, 53, 242-256.

Hubbard, T. L., \& Ruppel, S. E. (2002). A possible role of naïve impetus in Michotte's "launching effect": Evidence from representational momentum. Visual Cognition, 9, 153-176.

Huttenlocher, J., Hedges, L. V., \& Duncan, S. (1991). Categories and particulars: Prototype effects in estimating spatial location. Psychological Review, 98, 352-376. doi:10.1037/0033-295X.98.3. 352

Jarosz, A. F., \& Wiley, J. (2014). What are the odds? A practical guide to computing and reporting Bayes factors. Journal of Problem Solving, 7(1), 2. doi:10.7771/1932-6246.1167

Johansson, G. (1973). Visual perception of biological motion and a model for its analysis. Perception \& Psychophysics, 14, 201-211. doi:10. 3758/BF03212378

Kelly, M. H., \& Freyd, J. J. (1987). Explorations of representational momentum. Cognitive Psychology, 19, 369-401.

Kensinger, E. A., O’Brien, J. L., Swanberg, K., Garoff-Eaton, R. J., \& Schacter, D. L. (2007). The effects of emotional content on realitymonitoring performance in young and older adults. Psychology and Aging, 22, 752-764. doi:10.1037/0882-7974.22.4.752

Kerzel, D., Jordan, J. S., \& Musseler, J. (2001). The role of perception in the mislocalization of the final position of a moving target. Journal of Experimental Psychology: Human Perception and Performance, 27, 829-840. doi:10.1037/0096-1523.27.4.829

Klein, S. B., Robertson, T. E., \& Delton, A. W. (2010). Facing the future: Memory as an evolved system for planning future acts. Memory \& Cognition, 38, 13-22. doi:10.3758/MC.38.1.13

Kuhbandner, C., Spitzer, B., \& Pekrun, R. (2011). Read-out of emotional information from iconic memory: The longevity of threatening stimuli. Psychological Science, 22, 695-700. doi:10.1177/ 0956797611406445

Laney, C., Campbell, H. V., Heuer, F., \& Reisberg, D. (2004). Memory for thematically arousing events. Memory \& Cognition, 32, 11491159.

Laney, C., Heuer, F., \& Reisberg, D. (2003). Thematically-induced arousal in naturally-occurring emotional memories. Applied Cognitive Psychology, 17, 995-1004. doi:10.1002/acp.951

Lench, H. C., \& Levine, L. J. (2005). Effects of fear on risk and control judgments and memory: Implications for health promotion messages. Cognition and Emotion, 19, 1049-1069.

Lerner, J. S., \& Keltner, D. (2001). Fear, anger, and risk. Journal of Personality and Social Psychology, 81, 146-159.

Loftus, E. F., Loftus, G. R., \& Messo, J. (1987a). Some facts about weapon focus. Law and Human Behavior, 11, 55-62.

Loftus, E. F., Schooler, J. W., Boone, S. M., \& Kline, D. (1987b). Time went by so slowly: Overestimation of event duration by males and females. Applied Cognitive Psychology, 1, 3-13. doi:10.1002/acp. 2350010103

Love, J., Selker, R., Marsman, M., Jamil, T., Dropmann, D., Verhagen, A. J., \& Wagenmakers, E.-J. (2015). JASP (Version 0.7) [Computer software]. Amsterdam, The Netherlands: JASP Project. Retrieved from https://jasp-stats.org 
MacLeod, C., \& Mathews, A. (2004). Selective memory effects in anxiety disorders: An overview of research findings and their implications. In D. Reisberg \& P. Hertel (Eds.), Memory and emotion (pp. 155-185). New York: Oxford University Press.

Mather, M., \& Nesmith, K. (2008). Arousal-enhanced location memory for pictures. Journal of Memory and Language, 58, 449-464. doi: 10.1016/j.jml.2007.01.004

Mather, M., \& Sutherland, M. R. (2009). Disentangling the effects of arousal and valence on memory for intrinsic details. Emotion Review, 1, 118-119.

Mather, M., \& Sutherland, M. R. (2011). Arousal-biased competition in perception and memory. Perspectives on Psychological Science, 6, 114-133. doi:10.1177/1745691611400234

Mathews, A., \& Klug, F. (1993). Emotionality and interference with color-naming in anxiety. Behaviour Research and Therapy, 31, $57-62$.

McLeod, P., \& Dienes, Z. (1996). Do fielders know where to go to catch the ball or only how to get there? Journal of Experimental Psychology: Human Perception and Performance, 22, 531-543. doi:10.1037/0096-1523.22.3.531

Morelli, F., \& Burton, P. A. (2009). The impact of induced stress upon selective attention in multiple object tracking. Military Psychology, 21, 81-97.

Munger, M. P., \& Minchew, J. H. (2002). Parallels between remembering and predicting an object's location. Visual Cognition, 9, 177-194.

Munger, M. P., Solberg, J. L., \& Horrocks, K. K. (1999). The relationship between mental rotation and representational momentum. Journal of Experimental Psychology: Learning, Memory, and Cognition, 25, $1557-1568$

Novak, D. L., \& Mather, M. (2009). The tenacious nature of memory binding for arousing negative items. Memory \& Cognition, 37, 945952. doi:10.3758/MC.37.7.945

Öhman, A., Flykt, A., \& Esteves, F. (2001). Emotion drives attention: Detecting the snake in the grass. Journal of Experimental Psychology: General, 130, 466-478. doi:10.1037/0096-3445.130. 3.466

Olds, J. M., Lanska, M., \& Westerman, D. L. (2014). The role of perceived threat in the survival processing memory advantage. Memory, 22, 26-35.

Phelps, E. A., Ling, S., \& Carrasco, M. (2006). Emotion facilitates perception and potentiates the perceptual benefits of attention. Psychological Science, 17, 292-299. doi:10.1111/j.1467-9280. 2006.01701.x

Pickel, K. L. (1999). The influence of context on the "weapon focus" effect. Law and Human Behavior, 23, 299-311.

Pratt, J., Radulescu, P. V., Guo, R. M., \& Abrams, R. A. (2010). It's alive! Animate motion captures visual attention. Psychological Science, 21, 1724-1730.

Prinz, W. (1984). Modes of linkage between perception and action. In W. Prinz \& A.-F. Sanders (Eds.), Cognition and motor processes (pp. 185-193). Berlin: Springer.

Quinlan, P. T. (2013). The visual detection of threat: A cautionary tale. Psychonomic Bulletin \& Review, 20, 1080-1101. doi:10.3758/ s13423-013-0421-4

Radvansky, G. A. (2005). Situation models, propositions, and the fan effect. Psychonomic Bulletin \& Review, 12, 478-483. doi:10.3758/ BF03193791

Reed, C. L., \& Vinson, N. G. (1996). Conceptual effects on representational momentum. Journal of Experimental Psychology: Human Perception and Performance, 22, 839-850. doi:10.1037/00961523.22.4.839

Riskind, J., Moore, R., \& Bowlby, L. (1995). The looming of spiders: The fearful perceptual distortion of movement and menace. Behaviour Research and Therapy, 33, 171-178.

Roediger, H. L., III, \& McDermott, K. B. (1995). Creating false memories: Remembering words not presented in lists. Journal of
Experimental Psychology: Learning, Memory, and Cognition, 21, 803-814. doi:10.1037/0278-7393.21.4.803

Ruppel, S. E., Fleming, C. N., \& Hubbard, T. L. (2009). Representational momentum is not (totally) impervious to error feedback. Canadian Journal of Experimental Psychology, 63, 49-58.

Sheth, B. R., \& Shimojo, S. (2001). Compression of space in visual memory. Vision Research, 41, 329-341. doi:10.1016/S00426989(00)00230-3

Skosnik, P. D., Chatterton, R. T., Swisher, T., \& Park, S. (2000). Modulation of attentional inhibition by norepinephrine and cortisol after psychological stress. International Journal of Psychophysiology, 36, 59-68.

Storbeck, J., \& Clore, G. L. (2005). With sadness comes accuracy; with happiness, false memory. Psychological Science, 16, 785-791.

Strickland, B., \& Keil, F. (2011). Event completion: event-based inferences distort memory in a matter of seconds. Cognition, 121, 409415.

Talarico, J. M., \& Rubin, D. C. (2003). Confidence, not consistency, characterizes flashbulb memories. Psychological Science, 14, 455461.

Terburg, D., Aarts, H., \& van Honk, J. (2012). Memory and attention for social threat: Anxious hypercoding-avoidance and submissive gaze aversion. Emotion, 12, 666-672. doi:10.1037/a0027201

Veuilleumier, P. (2005). How brains beware: Neural mechanisms of emotional attention. Trends in Cognitive Sciences, 9, 585-594. doi:10. 1016/j.tics.2005.10.011

Vinson, N. G., \& Reed, C. L. (2002). Sources of object-specific effects in representational momentum. Visual Cognition, 9, 41-65. doi:10. 1080/13506280143000313

Werner, S., \& Diedrichsen, J. (2002). The time course of spatial memory distortions. Memory \& Cognition, 30, 718-730. doi:10.3758/ BF03196428

Wessel, I., \& Merckelbach, H. (1997). The impact of anxiety on memory for details in spider phobics. Applied Cognitive Psychology, 11, 223-231.

West, G. L., Anderson, A. A. K., \& Pratt, J. (2009). Motivationally significant stimuli show visual prior entry: Evidence for attentional capture. Journal of Experimental Psychology: Human Perception and Performance, 35, 1032-1042. doi:10.1037/a0014493

Wilson, M., Lancaster, J., \& Emmorey, K. (2010). Representational momentum for the human body: awkwardness matters, experience does. Cognition, 116, 242-250.

Winkielman, P., Niedenthal, P., \& Oberman, L. (2008). The embodied emotional mind. In G. R. Semin \& E. R. Smith (Eds.), Embodied grounding: Social, cognitive, affective, and neuroscientific approaches (pp. 263-288). New York: Cambridge University Press.

Witt, J. K., \& Brockmole, J. R. (2012). Action alters object identification: Wielding a gun increases the bias to see guns. Journal of Experimental Psychology: Human Perception and Performance, 38, 1159-1167. doi:10.1037/a0027881

Witt, J. K., \& Sugovic, M. (2013). Spiders appear to move faster than non-threatening objects regardless of one's ability to block them. Acta Psychologica, 143, 284-291. doi:10.1016/j.actpsy.2013.04. 011

Woody, S., \& Teachman, B. A. (2000). Behavior in relation to spiders: Disgust and fear. Paper presented at the annual meeting of the Association for the Advancement of Behavior Therapy, New Orleans, LA.

Yoshikawa, S., \& Sato, W. (2008). Dynamic facial expressions of emotion induce representational momentum. Cognitive, Affective, \& Behavioral Neuroscience, 8, 25-31. doi:10.3758/CABN.8.1.25

Zadra, J. R., \& Clore, G. L. (2011). Emotion and perception: The role of affective information. Wiley Interdisciplinary Reviews: Cognitive Science, 2, 676-685. 